\title{
OS IMPACTOS DA IMPLANTAÇÃO DO REGISTRO DE PONTO BIOMÉTRICO NAS HORAS EXTRAS EM UMA EMPRESA DO SETOR SUCROENERGÉTICO: um estudo de caso
}

\author{
THE IMPACTS OF BIOMETRIC TIME REGISTER IMPLEMENTATION ON \\ OVERTIME IN A SUGARCANE COMPANY: a case study
}

\author{
Arnaldo José Simedo \\ Mariana Bárbara Lopes Simedo ${ }^{\text {II }}$
}

\begin{abstract}
RESUMO
O avanço tecnológico tem possibilitado a melhoria constante de processos nas organizações, por meio de otimização de tempo, redução de custos, maior segurança, entre outros. Cada vez mais, o reconhecimento biométrico está presente no cotidiano das pessoas, seja em seus smartphones, caixas eletrônicos, aeroportos e, mais recentemente, nas urnas eletrônicas. Em meio a esse contexto, o presente trabalho buscou analisar como a implantação do ponto biométrico pode influenciar na quantidade de horas extras registradas. Para tanto, foi realizada uma pesquisa descritiva de caráter quantitativo, tendo como instrumento de coleta de dados a análise documental. Foram avaliados os relatórios de hora extra e adicional noturno dos 54 meses anteriores e 54 meses posteriores à introdução do projeto. Os resultados indicaram que, após a adoção da nova tecnologia, houve redução na quantidade de horas extras e adicional noturno, além do aumento das horas falta, o que ocasionou redução de custo com a folha de pagamento. Concluiu-se que a tecnologia biométrica foi responsável pela redução de 55.825 horas extras em um período de 54 meses, gerando para a empresa uma economia estimada de $\mathrm{R} \$ 426.327,00$.
\end{abstract}

Palavras-chave: Biometria. Ponto Eletrônico. Relógio de Ponto. Hora Extra. Custo.

\begin{abstract}
Technological advancement has enabled to constantly improve processes in organizations, through optimization of time, cost reduction, greater security, among others. Increasingly, biometric recognition is present daily, in people's smartphones, atms, airports and, more recently, in electronic voting machines. In this context, the present work sought to evaluate analyze how the implementation of the biometric time register can influence the amount of overtime work recorded. For that, a descriptive research of quantitative character was carried out, having as instrument of data collection the documentary analysis. The reports of

\footnotetext{
${ }^{\prime}$ Mestrando em Administração pela Universidade Estadual Paulista (UNESP) de Jaboticabal - São Paulo - Brasil. E-mail: arnaldo165@gmail.com.

" Doutoranda em Agronomia pela Universidade Estadual Paulista (UNESP) de Jaboticabal - São Paulo - Brasil. Email: mariana_blopes@hotmail.com.
} 


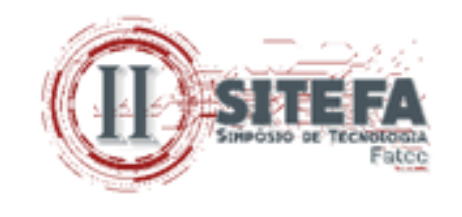

overtime, nighttime overtime and time missed from the previous four years and four years after the project introduction were evaluated. The results indicated that, after the adoption of the new technology, there was a reduction in the amount of overtime and additional night work, in addition to an increase in the hours missed, which causes a reduction of the cost with the payroll. It was concluded that biometrics was responsible for the reduction of 55.825 overtime in 54 months, generating an estimated cost savings of $R \$ 426.327,00$ for the company.

Keywords: Biometry. Electronic Time Attendance. Time register. Overtime work. Cost.

Data de submissão do artigo: 15/07/2019.

Data de aprovação do artigo: 13/09/2019.

DOI:

\section{INTRODUÇÃO}

O setor sucroenergético possui grande importância socioeconômica para o país, uma vez que emprega direta e formalmente mais de 950 mil pessoas, além de 70 mil produtores de cana independentes. Também é responsável pela movimentação superior a U\$100 bilhões por meio de, aproximadamente, 380 unidades produtoras cujas atividades estão presentes em mais de mil municípios (UNICA, 2016).

O local de trabalho descentralizado e a grande quantidade de colaboradores nas usinas de cana de açúcar dificultam o monitoramento das atividades, facilitando a prática de ações oportunistas que são supostos comportamentais estudados na Teoria dos Custos de Transação (TCT). Comportamento oportunista pode ser definido como a execução de uma ação visando interesse próprio, sem se preocupar com a outra parte da relação (SHERVANI; FRAZIER; CHALLAGALLA, 2007).

Souza, Meurer e Schmidt (2013), afirmam que os custos de transação existem também no ambiente de trabalho por se tratar de interação entre indivíduos, citando como exemplo o fato de o colaborador poder não cumprir com todas as tarefas delegadas a ele, bem como o empregador poder se aproveitar do trabalho do funcionário acima do estipulado.

Nesse sentido, com o objetivo de disciplinar o registro eletrônico de ponto, o Ministério do Trabalho criou, em 21 de agosto de 2009, a portaria no 1.510 (BRASIL, 2009) e, em 25 de fevereiro de 2011, a portaria 373 (BRASIL, 2011). De acordo com artigo 74 da CLT, todos os estabelecimentos com mais de dez empregados são obrigados a realizar anotação de entrada e saída, em registro manual, mecânico ou eletrônico (BRASIL, 1943).

De acordo com a legislação, as empresas precisaram investir em novos equipamentos para continuar registrando eletronicamente o ponto de seus colaboradores. Diante do advento da identificação biométrica, iniciado no projeto piloto das eleições em 2008 (ABREU; SMITH, 2017) e do investimento a ser realizado, parte das organizações optaram por se adequar às novas leis, utilizando equipamentos com tecnologia de reconhecimento biométrico.

Diante disso, o presente trabalho tem como objetivo geral analisar como a implantação do ponto biométrico pode influenciar na quantidade de horas extras registradas. Essa pesquisa pode ser considerada relevante do ponto de vista acadêmico, pois aborda um tema pouco explorado na área da tecnologia: a utilização da identificação biométrica e seus efeitos nas 


\section{(10)}

organizações privadas. Além disso, os resultados contribuem para estudos de viabilidade de projetos com biometria.

\section{REVISÃO BIBLIOGRÁFICA}

Nesta seção serão abordados os principais aspectos relacionados à biometria e legislação vigente a fim de embasar teoricamente o estudo.

\subsection{Biometria}

A identificação biométrica refere-se ao processo de reconhecimento automatizado de indivíduos, baseado em suas características comportamentais ou biológicas (JAIN; ROSS, 2015). Segundo Mordini e Massari (2008), qualquer característica biológica ou comportamental pode ser utilizada como um identificador biométrico, desde que satisfaça quatro requisitos básicos: mensurabilidade (pode ser medido), universalidade (existe em todas as pessoas), unicidade (distinto para cada indivíduo) e permanência (se mantém ao longo do tempo).

Podem ser citados como exemplos de características biológicas: impressões digitais, geometria das mãos ou palma, retina, íris e traços faciais; como aspectos comportamentais temos: assinatura, tom de voz, caminhar, padrão de pressionamento de teclas, entre outros (JAIN; ROSS; PRABHAKAR, 2004; KALUNGA; TEMBO, 2016). Durante quase um século, apenas a digital satisfez esses parâmetros. Para Abreu e Smith (2017), a identificação pela digital é a mais aceita dentre todos os métodos.

Os sistemas biométricos automatizados só se tornaram disponíveis nas últimas décadas, devido aos avanços da tecnologia da informação, no entanto, são baseados em ideias que foram concebidas centenas de anos atrás. $\mathrm{O}$ desenvolvimento no campo da biometria é crescente, deixando as tecnologias cada vez mais confiáveis e baratas. (VERMA; KHAN, 2016).

O sucesso do reconhecimento biométrico na área forense, juntamente com as crescentes preocupações relacionadas à segurança eletrônica, controle de imigração e fraudes financeiras têm gerado grande interesse na utilização de impressões digitais, bem como outras características, para identificação de pessoas. Por isso, é cada vez mais comum ver a biometria permeando vários segmentos da sociedade, como: segurança de smartphone, sistemas bancários, acesso a áreas restritas e registro civil (JAIN; ROSS, 2015).

Sua popularidade também pode ser justificada pelo fato dos traços biométricos, como impressão digital e a característica da íris permanecerem os mesmos durante a vida útil, além de não poderem ser perdidos como cartões ou esquecidos e adivinhados como senhas, que são baseados em códigos de identificação (MODAK; JHA, 2018; TROCCHIA; AINSCOUGH, 2006).

O Brasil é conhecido por introduzir diversas formas de utilização de tecnologias baseadas em biometria para autenticação. Um bom exemplo de aplicação biométrica que, inclusive, está sendo implementada no país, é o sistema de votação. O Tribunal Superior Eleitoral (TSE) lançou, em 2008, um projeto piloto de voto biométrico, que foi aprovado e utilizado de forma oficial nas eleições seguintes (ABREU; SMITH, 2017).

De acordo com o TSE (2018), 59,31\% dos eleitores, ou seja, mais de 87 milhões de pessoas já estão com a digital cadastrada. Segundo Abreu e Smith (2017), depois que esse 


\section{(II) SITEFA}

banco de dados estiver completo, será o maior sistema de identificação biométrica do mundo, baseado em impressões digitais.

Para Verma e Khan (2016), a biometria pode evitar fraudes como o buddy punching termo em inglês utilizado para definir a ação de um funcionário registrar o ponto no lugar de outro, além de melhorar a segurança do ambiente, o processo de apuração do ponto, gerando precisão nos cálculos, reduzindo custos com a folha de pagamento e, consequentemente, economizando dinheiro, tempo e recursos. De acordo com Akinduyite et al. (2013), outra vantagem da biometria é a eliminação do custo com aquisição de cartões.

\subsection{Legislação}

$\mathrm{O}$ artigo 74 , parágrafo $2^{\circ}$ da CLT determina que, em empresas com mais de dez empregados, deve o empregador manter o registro diário dos horários de trabalho realizados pelo trabalhador. $\mathrm{O}$ apontamento pode ser realizado de forma manual (livro de ponto), eletrônico (registro eletrônico) e mecânico (relógio de ponto cartográfico), (BRASIL, 1943).

Em 25 de agosto de 2009, foi criada pelo ministério do trabalho a portaria 1510, com o objetivo de regulamentar o registro de ponto eletrônico no país. O novo equipamento foi denominado Registrador Eletrônico de Ponto (REP), conforme artigo $3^{\circ}$ :

Art. $3^{\circ}$ Registrador Eletrônico de Ponto - REP é o equipamento de automação utilizado exclusivamente para o registro de jornada de trabalho e com capacidade para emitir documentos fiscais e realizar controles de natureza fiscal, referentes à entrada e à saída de empregados nos locais de trabalho (BRASIL, 2011).

As principais diferenças do REP em relação aos relógios de ponto convencionais estão especificadas no artigo $4^{\circ}$ :

Art. $4^{\circ} \mathrm{O}$ REP deverá apresentar os seguintes requisitos:

I - relógio interno de tempo real com precisão mínima de um minuto por ano com capacidade de funcionamento ininterrupto por um período mínimo de mil quatrocentos e quarenta horas na ausência de energia elétrica de alimentação;

II - mostrador do relógio de tempo real contendo hora, minutos e segundos;

III - dispor de mecanismo impressor em bobina de papel, integrado e de uso exclusivo do equipamento, que permita impressões com durabilidade mínima de cinco anos;

IV - meio de armazenamento permanente, denominado Memória de Registro de Ponto - MRP, onde os dados armazenados não possam ser apagados ou alterados, direta ou indiretamente;

V - meio de armazenamento, denominado Memória de Trabalho - MT, onde ficarão armazenados os dados necessários à operação do REP;

VI - porta padrão USB externa, denominada Porta Fiscal, para pronta captura dos dados armazenados na MRP pelo Auditor- Fiscal do Trabalho;

VII - para a função de marcação de ponto, o REP não deverá depender de qualquer conexão com outro equipamento externo; e

VIII - a marcação de ponto ficará interrompida quando for feita qualquer operação que exija a comunicação do REP com qualquer outro equipamento, seja para carga ou leitura de dados (BRASIL, 2011).

A Portaria 373 permite aos empregadores utilizarem outros sistemas eletrônicos até então não previstos na portaria anterior, desde que conste em acordo ou convenção coletiva de trabalho (BRASIL, 2011). Como ponto principal da portaria, temos: 




Art. $3^{\circ}$ - Os sistemas alternativos eletrônicos não devem admitir:
I - restrições à marcação do ponto;
II - marcação automática do ponto;
III - exigência de autorização prévia para marcação de sobrejornada; e
IV - a alteração ou eliminação dos dados registrados pelo empregado.
§ $1^{\text {o }}$ - Para fins de fiscalização, os sistemas alternativos eletrônicos deverão:
I - estar disponíveis no local de trabalho;
II - permitir a identificação de empregador e empregado; e
III - possibilitar, através da central de dados, a extração eletrônica e impressa do
registro fiel das marcações realizadas pelo empregado (BRASIL, 2011).

Levando em consideração a necessidade de investimento para substituir os relógios de ponto convencionais por equipamentos adequados às novas legislações, empresas passaram a aderir a biometria como meio de registro do ponto.

\section{MATERIAIS E MÉTODOS}

Foi realizada uma pesquisa bibliográfica para construção do referencial teórico. Para isso, foram consultados documentos nas principais bases de dados científicos, como Scopus e Web of Science, além da utilização de legislações vigentes no país. Segundo Cervo, Bervian e Silva (2007), a pesquisa bibliográfica busca explicar um determinado assunto a partir de contribuições culturais e cientificas do passado. Desenvolveu-se uma pesquisa descritiva de caráter quantitativo, tendo como instrumento de coleta de dados a análise documental. Segundo Sá-Silva, Almeida e Guindane (2009), essa metodologia é capaz de produzir ou reelaborar conhecimentos, criando formas de compreender fenômenos.

O objeto de estudo do presente trabalho foi uma usina produtora de etanol do Estado do Mato Grosso (MT). A escolha da empresa se deu, primeiramente, pelo seu porte e por questões de conveniência, devido ao fato de ter aceitado participar do estudo.

O controle de ponto biométrico foi implantado oficialmente em julho de 2014, mês em que se iniciou a contabilização das horas registradas no relógio de ponto eletrônico. Registros anteriores, na fase de implantação, não foram considerados, ou seja, não foram integrados à base de dados oficial. Os funcionários cujos registros de ponto foram avaliados são do setor administrativo e industrial, não fazendo parte desse estudo a área agrícola, cuja forma de controle de ponto se manteve o mesmo.

Para avaliar os impactos decorrentes da implantação, foram analisados relatórios gerados pelo módulo de Recursos Humanos (RH)/Departamento Pessoal contidos no sistema Enterprise Resource Planning (ERP) da empresa. Os parâmetros analisados foram: hora extra $50 \%$ e $100 \%$, adicional noturno e hora falta. Os relatórios foram gerados individualmente por parâmetro e ano, contendo o total mensal de cada item avaliado. O ERP não fornecia opção para geração de tais dados de forma agrupada. Sendo assim, ao todo, 32 arquivos foram gerados e sistematizados em um único documento, utilizando o software Excel® 2016.

Para proporcionar uma melhor comparação das informações, foi realizado um recorte temporal dos dados no período dos anos de 2010 a 2018. Esse intervalo de tempo foi selecionado pois, gera um histórico significativo de informações e, também, a mesma quantidade de dados anteriores e posteriores à implantação. 


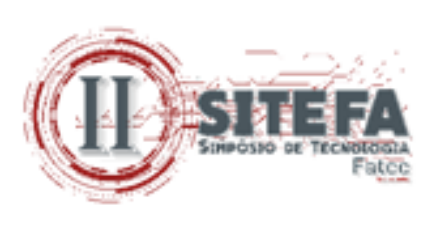

\section{RESULTADOS E DISCUSSÃO}

Para compreender os impactos gerados pela implantação do ponto eletrônico, analisou-se os componentes do salário que são afetados pela quantidade de horas trabalhadas ao longo do dia: hora extra $50 \%$ e $100 \%$, adicional noturno e hora falta. Para facilitar a compreensão dos resultados, os dados serão apresentados em forma de gráficos. O período analisado anterior à implantação é de janeiro de 2010 a junho de 2014, enquanto o posterior a implantação inicia-se em julho de 2014, concluindo em dezembro de 2018.

\subsection{Quantidade de funcionários}

Conforme demonstrado no gráfico 1, o quadro de funcionários não apresentou grandes variações, mantendo-se na maior parte do tempo entre a faixa de 200 a 400 colaboradores. A média de funcionários no período anterior à implantação foi de 376, com quantidade mínima de 208 registrada em janeiro de 2011 e máxima de 763 no mês de abril do mesmo ano. No período posterior à implantação, a média de colaboradores foi de 342 , tendo o valor mínimo de 221 apresentados em dezembro de 2015 e o máximo de 510 em março do ano seguinte.

Gráfico 1 - Comparação do total de funcionários ao longo do tempo

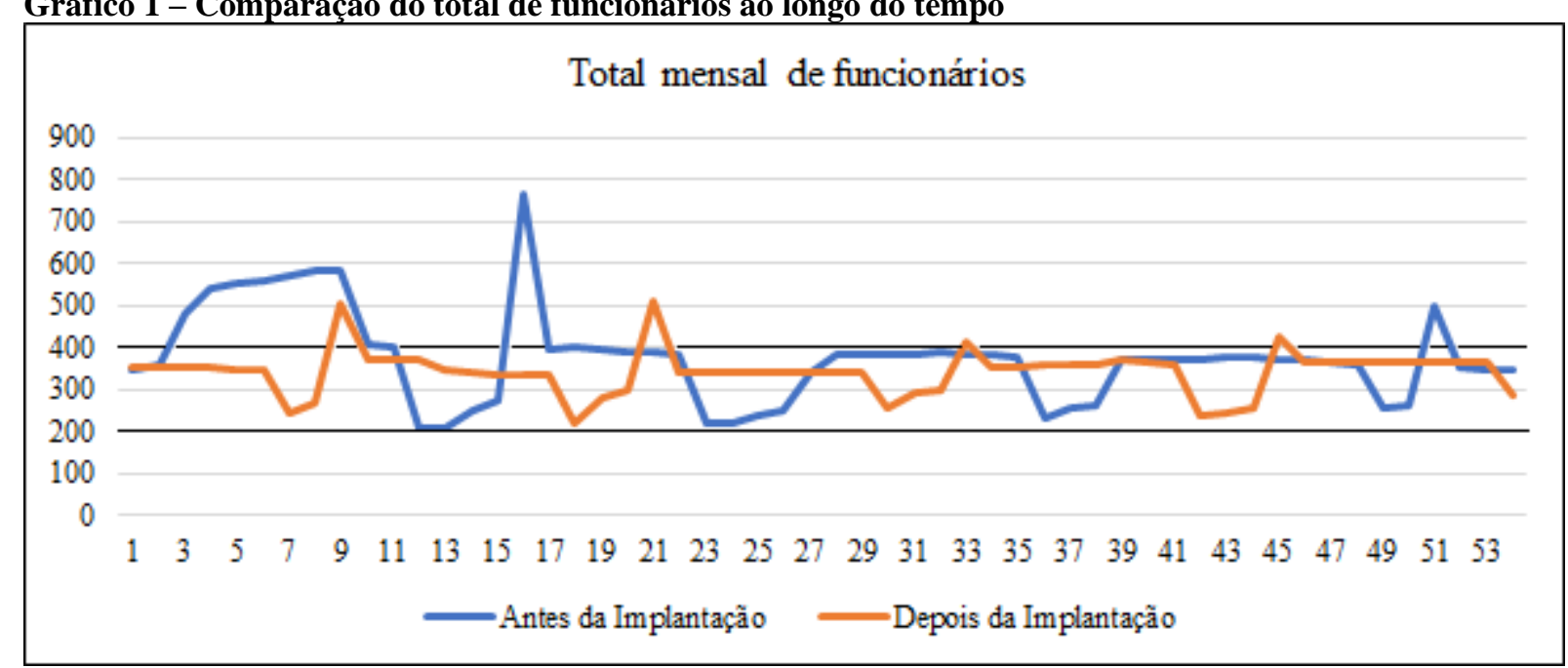

Fonte: elaborado pelos autores (2019)

Comparando a média geral de cada período, observa-se que houve uma redução de aproximadamente 9\% dos funcionários após a implantação, passando de 376 para 342. Esse dado demonstra que a quantidade de funcionários não colaborou para uma possível redução dos parâmetros analisados posteriormente. 


\section{(10)}

\subsection{Horas Extras 50\%}

As horas extras foram analisadas separadamente. Primeiramente, foram avaliadas as horas com acréscimo de $50 \%$ do valor. Conforme demonstrado no gráfico 2, de forma geral, houve uma redução na quantidade.

\section{Gráfico 2 - Comparação da quantidade total de hora extra $50 \%$ ao longo do tempo}

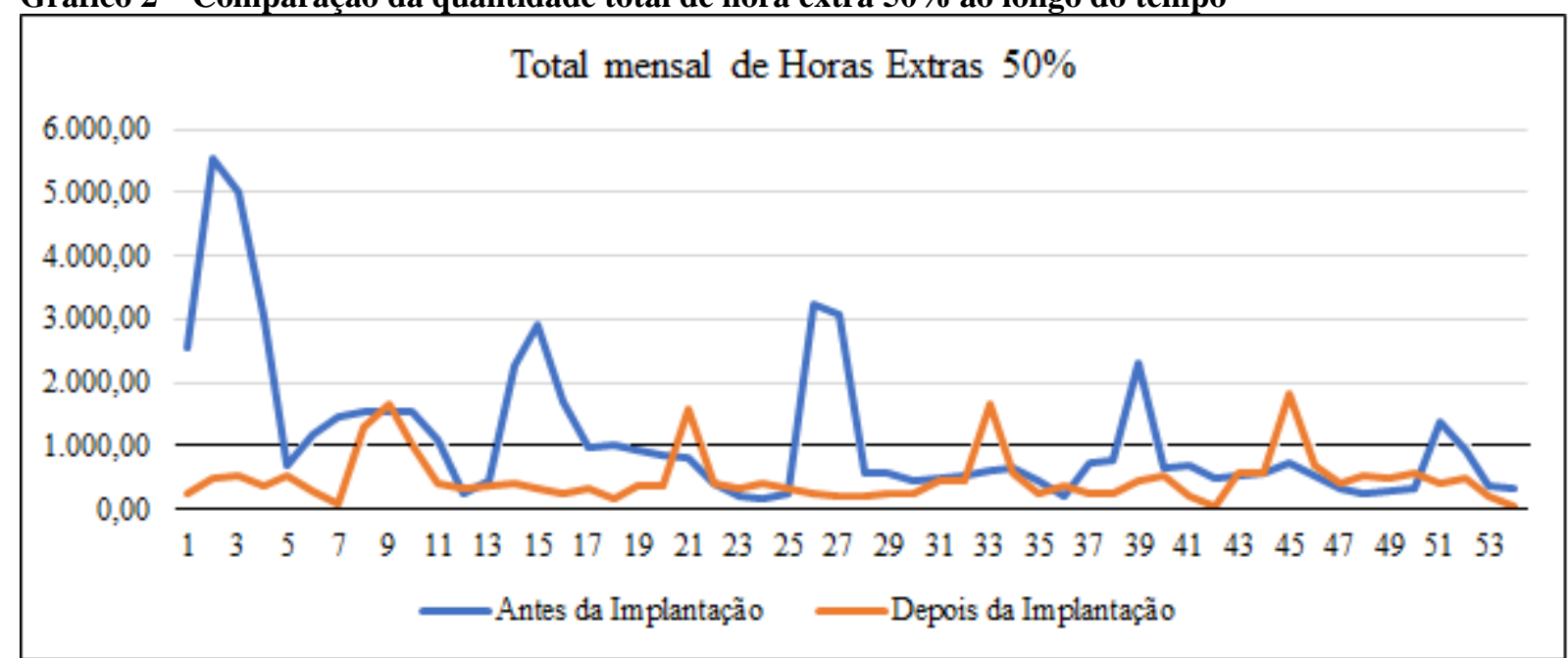

Fonte: elaborado pelos próprios autores (2019)

Após a implantação, a quantidade total mensal se manteve, em sua maioria, até o limite máximo de mil, superando tal valor em apenas 6 dos 54 meses analisados, enquanto no período anterior, esse valor foi superado em 18 meses. A soma total de horas registradas anteriormente à implantação foi de 61.722 , com média mensal de 1.143 , enquanto o período posterior contou com um total de 26.382 , cuja média foi de 488 , ou seja, uma redução de aproximadamente $57 \%$.

\subsection{Horas Extras 100\%}

A quantidade de horas extras com acréscimo de $100 \%$ sofreu grande variação ao longo do tempo, conforme demonstrado no gráfico 3. Diferente das horas extras $50 \%$, o percentual de redução se mostrou mais moderado. 


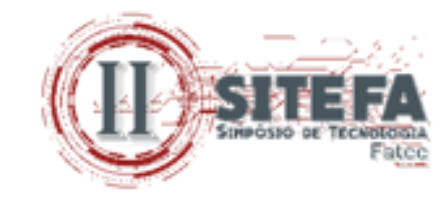

Gráfico 3 - Comparação da quantidade total de hora extra $100 \%$ ao longo do tempo

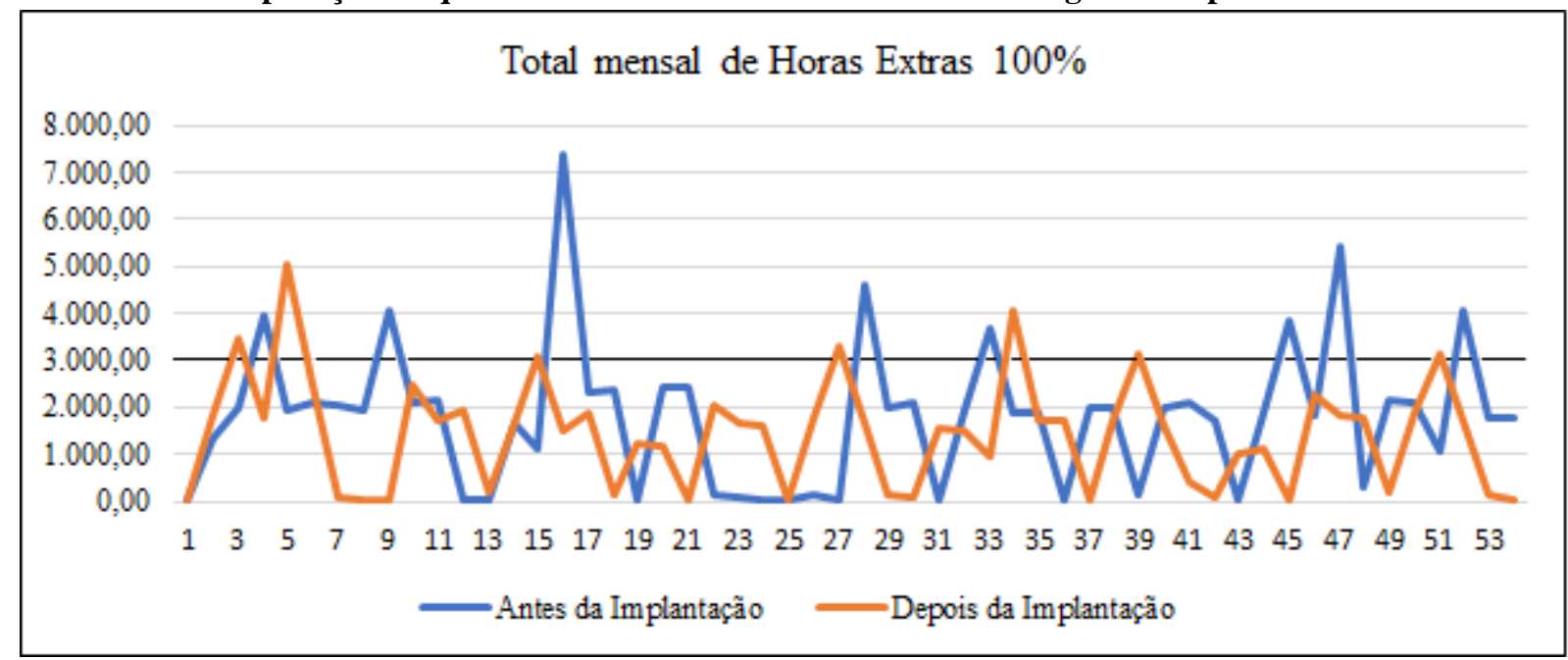

Fonte: elaborado pelos próprios autores (2019)

O total de horas extras $100 \%$ antes da implantação foi de 97.986 , tendo como média mensal 1.814 horas, enquanto o período posterior registou um total de 77.501 cuja média foi de 1.345 , representando uma redução de aproximadamente $21 \%$.

\subsection{Adicional Noturno}

A quantidade de horas pagas com adicional noturno apresenta um comportamento padrão, demonstrando quedas bruscas em determinados meses, conforme exibido no gráfico 4. Esse padrão apresentado se justifica pela ocorrência da entressafra, na qual a empresa interrompe a produção, com consequente redução da demanda por trabalho noturno.

Gráfico 4 - Comparação da quantidade total de adicional noturno ao longo do tempo

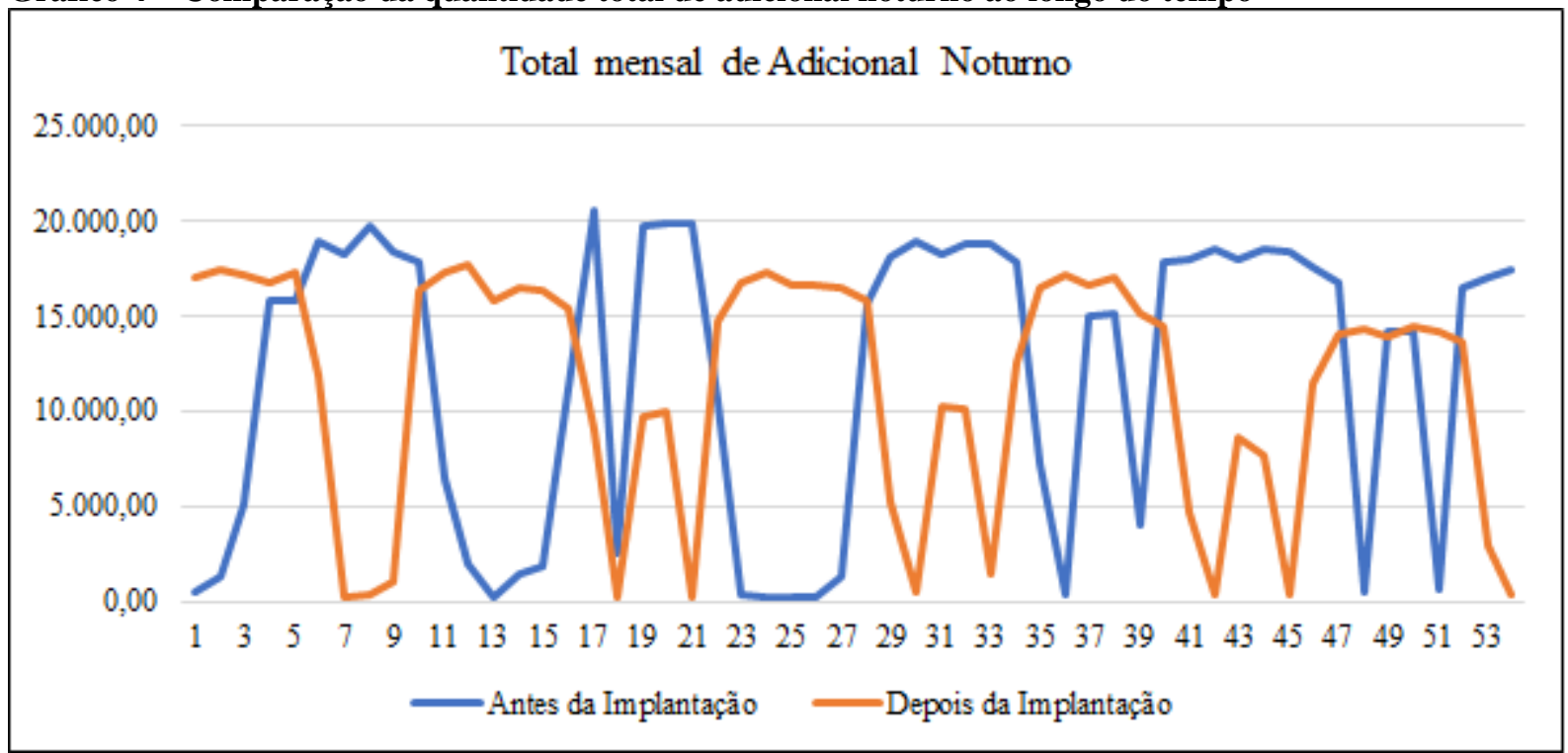

Fonte: elaborado pelos próprios autores (2019) 


\section{(1010)}

As horas com pagamento de adicional noturno apresentou um total de 642.360 e média mensal de 11.895 no período anterior à implantação do projeto, enquanto posteriormente foi registrado um total de 615.917, com média de 11.405 por mês. Ao se comprar os dois períodos, observa-se uma redução de aproximadamente $4 \%$. O pequeno percentual se justifica pelo fato de as horas de adicional noturno serem consideradas apenas em uma fração do dia.

\subsection{Horas falta}

As horas relativas ao atraso dos funcionários tiveram um aumento considerável, que pode ser observado no gráfico 5.

Gráfico 5 - Comparativo da quantidade total de horas falta ao longo do tempo

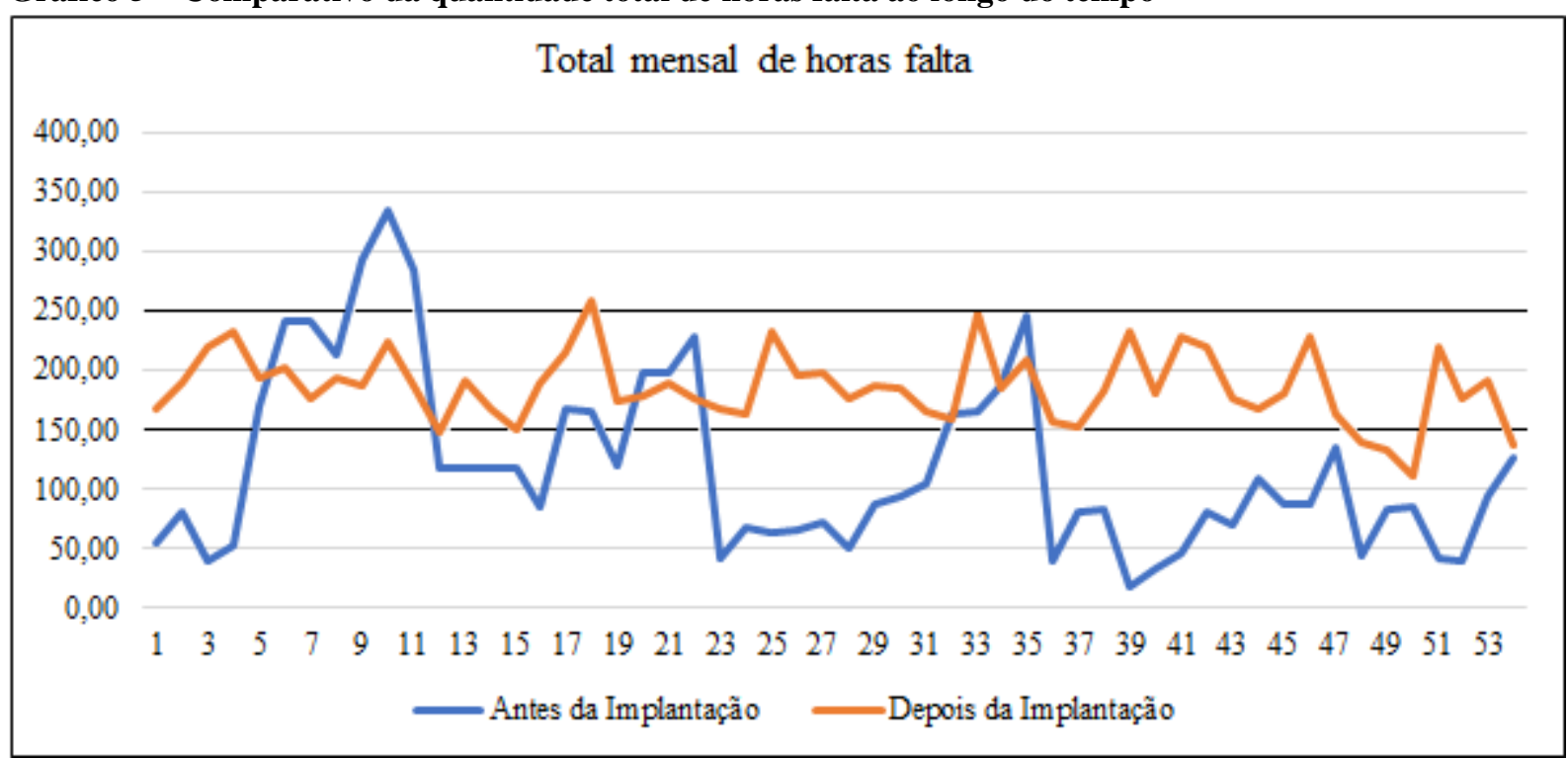

Fonte: elaborado pelos próprios autores (2019)

Antes da implantação, as horas falta se concentravam, em sua maior parte, até o limite de 150, tendo ultrapassado esse número em 16 dos 54 meses, enquanto no período posterior, foram 48 vezes, ou seja, apenas em seis meses, esse limite não foi atingido. Após a implantação do projeto, o total de horas falta passou de 6.412 para 10.042 , o que representou um aumento de aproximadamente 56\%. A média mensal foi de 118 para 185 horas.

\subsection{Resultados Globais}

Para facilitar a visualização dos resultados de forma geral, foi criada a tabela 1, que sintetiza os valores obtidos, comparando os dois períodos. 


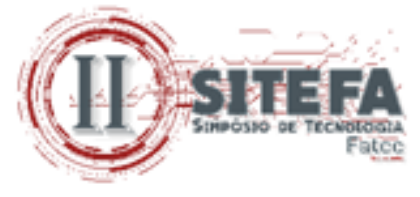

Tabela 1 - Resumo comparativo do antes e depois da implantação

\begin{tabular}{ccccc}
\hline Parâmetros & $\begin{array}{c}\text { Antes } \\
\text { jan/2010 - jun/2014 }\end{array}$ & $\begin{array}{c}\text { Depois } \\
\text { jul/2014 - dez/2018 }\end{array}$ & Diferença & Variação \\
\hline Média de Funcionários & 376 & 342 & 34 & $-9,04$ \\
Total de Horas Extras 50\% & 61.722 & 26.382 & 35.340 & $-57,26$ \\
Total de Horas Extras 100\% & 97.986 & 77.501 & 20.485 & $-20,91$ \\
Acumulado Horas Extra & 159.708 & 103.883 & 55.825 & $-34,95$ \\
Total de Horas de Adicional & 642.360 & 615.917 & 26.443 & $-4,12$ \\
Noturno & 6.412 & 10.042 & 3.630 & $+56,61$ \\
\hline Total de Horas Falta & & & & \\
\hline
\end{tabular}

Fonte: elaborada pelos próprios autores (2019)

Tomando por base o salário mínimo atual de R $\$ 998,00$ (BRASIL 2019), e uma jornada de trabalho de 8 horas diárias, o valor de uma hora com acréscimo de $50 \%$ é R $\$ 6,80$, enquanto $100 \%$ resulta em $\mathrm{R} \$ 9,07$. Desse modo, considerando apenas a redução das horas extras, destaca-se uma economia total estimada de, aproximadamente, $\mathrm{R} \$ 426.327,00$.

\section{CONCLUSÃO}

Este trabalhou procurou investigar como a implantação do registro de ponto biométrico impactou no cômputo das horas extras, mediante análise documental dos relatórios que possibilitou comparar o período anterior ao posterior à implantação.

Concluiu-se com esse estudo que a tecnologia biométrica foi responsável pela redução de 55.825 horas extras em um período de 54 meses, gerando para a empresa uma economia estimada de $\mathrm{R} \$ 426.327,00$.

Entende-se que os objetivos da pesquisa foram alcançados, demonstrando assim que a metodologia proposta foi adequada, levando a obtenção de resultados relevantes para a organização.

Este estudo possui algumas limitações, as quais podem servir como proposta para trabalhos futuros. A pesquisa foi realizada em uma única organização, podendo ser expandida para outras empresas, a fim de se gerar um comparativo entre elas. Para pesquisas futuras, sugere-se realizar as análises individualizadas por setor, sendo possível definir quais foram mais sensíveis à implantação. Por não ter acesso aos valores, não foi possível calcular com exatidão os valores economizados com pagamento de hora extra.

\section{REFERÊNCIAS}

ABREU, M. C.; SMITH S. Using biometric-based identification systems in Brazil: A review on low cost fingerprint techniques on-the-go. Computer Law \& Security Review. Vol 33, p 629-634, 2017.

AKINDUYITE C.O; ADETUNMBI A.O; OLABODE, O.O, and Ibidunmoye E.O, "Fingerprint-Based Attendance Management System." Journal of Computer Sciences and Applications 1, no. 5 (2013): 100-105. doi: 10.12691/jcsa-1-5-4. 
BRASIL. CLT- Consolidação das Leis do Trabalho. 1943. Aprova a Consolidação das Leis do Trabalho. Disponível em: http://www.planalto.gov.br/ccivil_03/decretolei/ del5452.htm. Acesso em: 20 out. 2018.

Decreto $\mathrm{N}^{\circ}$ 9.661, de 01 de janeiro de 2019. Dispõe sobre o valor do salário mínimo e a sua política de valorização de longo prazo. Diário Oficial da União, 01 jan. 2019.

Ministério de Estado do Trabalho e Emprego. Portaria $\mathrm{N}^{\circ} 1.510$, de 21 de agosto de 2009. Regulamenta o registro eletrônico de ponto e a utilização do Sistema de Registro Eletrônico de Ponto - SREP. Diário Oficial da União, 25 ago 2009.

Ministério de Estado do Trabalho e Emprego. Portaria $\mathrm{N}^{\circ} 373$, de 25 de fevereiro de 2011. Dispõe sobre a possibilidade de adoção pelos empregadores de sistemas alternativos de controle de jornada de trabalho. Diário Oficial da União, 28 ago 2011.

CERVO, A.L.; BERVIAN, P.A.; SILVA, R. Metodologia científica. 6. ed. São Paulo: Pearson Prentice Hall, 2007.

JAIN, A. K.; ROSS, A. Bridging the gap: From biometrics to forensics. Philosophical Transactions of the Royal Society B: Biological Sciences, v. 370, n. 1674, p. 1-11, 2015.

JAIN, A. K.; ROSS, A.; PRABHAKAR, S. An Introduction to Biometric Recognition. IEEE Transactions on Circuits and Systems for Video Technology, v. 14, n. 1, p. 4-20, 2004.

KALUNGA, J.; TEMBO, S. Development of Fingerprint Biometrics Verification and Vetting Management System. American Journal of Bioinformatics Research, v. 6, n. 3, p. 99-112, 2016.

MODAK, S. K. S.; JHA, V. K. Multibiometric Fusion strategy and its Applications: A Review. Information Fusion, v. 49, n. January 2018, p. 174-204, 2018. Disponível em: https://doi.org/10.1016/j.inffus.2018.11.018.

MORDINI, E.; MASSARI, S. Body, Biometrics and Identity. Bioethics, v. 22, n. 9, p. 488498, nov. 2008.

SÁ-SILVA, J.R.; ALMEIDA, C.D.; GUINDANE, J.F. Pesquisa documental: pistas teóricas e metodológicas. Revista Brasileira de História \& Ciências Sociais, v.1, n.1, p.1-15, 2009.

SHERVANI, T.A.; FRAZIER, G; CHALLAGALLA, G. The moderating influence of firm market power on the transaction cost economics model: an empirical test in a forward channel integration context. Strategic Management Journal. vol. 28, p. 635-52, 2007.

SOUZA E. L. C., MEURER A. P. S., SCHMIDT C. M Ativos específicos no mercado de trabalho: uma abordagem à luz da economia dos custos de transação. Revista Eletrônica Gestão e Serviços. vol. 4, n 2, p. 587-609, jul/dez 2013

TRIBUNAL SUPERIOR ELEITORAL. Estatísticas Eleitorais. Brasília, dezembro de 2018. 




Disponível em: http://www.tse.jus.br/eleicoes/estatisticas/estatisticas-eleitorais. Acesso em: 04 dez 2018.

TROCCHIA, P.J., AINSCOUGH, T.L. Characterising consumer concerns about identification technology. International Journal of Retail and Distribution Management 34 (8), 609620, 2006.

UNIÃO DA INDÚSTRIA DE CANA-DE-AÇÚCAR - ÚNICA. Setor sucroenergético no Brasil uma visão para 2030. São Paulo, outubro de 2016. Disponível em:9 http://www.mme.gov.br/documents/10584/7948692/UNICACEISE_Setor+Sucroenerg\%C3\% A9tico+no+Brasil_Uma+Vis\%C3\%A3o+para+2030.pdf/80da9580-60c7-4f53-afaf030ad01f3ebf; jsessionid=AC802B166C93389BED1AB445EAB7CD10.srv155. Acesso em: 01 jul. 2018.

VERMA, D. M.; KHAN, D. N. A Study on Benefits of Biometrics Attendance System: A Technological based Human Resource Management Practice. TMIMT International Journal, Edição Especial, 2016. 